\title{
Development and Validation of Parent-Adolescent Relationship Scale (PARS)
}

\section{Seyyedeh Fatemeh Husseini}

\author{
Faculty of Psychology, Islamic Azad University of Karaj
}

\section{Bagher Sanaee Zakir}

PhD in Counseling and professor at faculty of Psychology, Islamic Azad University of Karaj

Reza Pourhossein

PhD in Psychology and Associate Professor at Faculty of Psychology and Education, Tehran University

Addis Karaskian

PhD in psychology and Assistant Professor at faculty of Psychology, Islamic Azad University of Karaj

\section{Doi:10.5901/mjss.2016.v7n5p419}

\section{Abstract}

This article was done to develop and validate a scale for measuring "Parent-Adolescent Relationship" based on Attachment Theory. After examination of face and content validity by experts, and pilot study 38 items were selected as a primary questionnaire. 273 students of 10 high-schools in region No.6 of Tehran, selected randomly, were given this questionnaire. Then factor analysis with 5 factor and promax rotation were applied, and final scale was extracted with 21 items. Also Cronbach's alpha coefficient (0.86) was used to verifying the reliability of scale, which presented the high internal consistency of it. For investigating the scale validity convergent and divergent validity are applied, in addition to examination of content validity by 11 psychologist experts, and construct validity with factor analysis. The result of this study represented that "ParentAdolescent Relationship Scale (PARS)" was included of 5 sub-scales which were: support, confidence, uncondional acceptance, cooperation, and common emotion.

Keywords: Factor Analysis, Parent-Adolescent Relationship Scale (PARS), Attachment Theory, Validity, Reliability

\section{Introduction}

Many experts have called adolescence as the period of storm and stress, i.e. a period between childhood and adulthood which is followed by biological, psychological, cognitive and social changes. The present research indicates significance of relationship between adolescents and their parents. Greenfield \& Suzuki (1998) know Parent-Adolescent Relationship (PAR) as an important facet of the development process of socialization of children, represented a bond between parent and adolescent and smoothened the process of transfer of intergenerational value and preparation of the adolescent to enter into the social world. Parent-Adolescent Relationship (PAR) transforms during adolescence and there is a significant relationship between the adolescent's adjustment and quality of this relationship. A loving relationship full of acceptance with parents provides health-oriented atmosphere for the growth of the child's abilities in diverse ways. Findings of research indicated that quality of Parent-Adolescent Relationship (PAR) associates to a wide range of positive outcomes including emotional and mental Well-being, adjustment with environment and social competence. Quality of this relationship correlates to reduction of behavioral problems in adolescence such as Substance abuse, delinquency and sexual unconventional behaviors (Borkowski et al. 2002; Hair et al. 2003). However nature of attachment during adolescence differs from attachment at childhood, adolescents require trust on parents' commitment to them. Adolescents require their parents as the safe shelters so as to explore the world by their advocacy (Baltes \& Silverberg, 1994). With regard to points of view of Marchel(2004), Parent-Adolescent Relationship serves as a pattern for the child's relationships in future, believed that quality of early relationships can forecast quality of person's next relationships. Allen \& Land (1999) believed that attachment in adolescence differentiates from the attachment in early relationships both in cognitive and behavioral level. From behavioral perspective, strong emotional interests to parents can by through kidding. 
Cognitive achievements in adolescent's mind lead to his more accountability in the activities such as monitoring and as the result his stronger parent-adolescent relationship. Other studies at this area indicate that attachment representations in the early years associate to the features of Parent-Adolescent Relationship in adolescence (Becker-Stoll \& FremmerBombik, 1997). Intimacy during childhood emerges in different forms than adolescence. For instance, the intimacy which is displayed by means of hugging reduces by arrival of the person to puberty. However, we witness increase in conversations in which information can be exchanged and emotions are expressed (Hartup, 1991). These adjustments are suitable responses to puberty level and needing to change in adolescents. It is evident that attachment theory puts emphasis on significance of close relationship between parent and adolescent and this theory conducts the researcher to find intimacy in parent-adolescent relationship.

\section{Literature Review on Parent-adolescent Relationship in Iranian Research}

Araghi(2008) in a research compared quality of parent-adolescent relationship among aggressive and non-aggressive students who were studying at secondary grade. He displayed that the father-child relationship enjoyed a higher quality in non-aggressive students than aggressive students in all the dimensions of relationship. Thus, it can conclude that the mutual child-parent relationship grounded on positive emotion and less anger can affect reduction or removal of children's anger. Maintenance of such a relationship allows the adolescent to control himself and make reasonable decisions about relationship with his parent in cases he is angry. Bahram Abadi et al.(2013) in an experimental research to improve quality of parent-child relationship in mother-headed families arranged an eight session program to train girl adolescents. This program in form of an educational workshop for effective relationship skills increased some sub-scales of childparent relationship, i.e. positive emotion and relationship, but no specific change has been reported about subscales of Identification with the mother and lack of confusion (Bahram Abadi et al. 2013). Another experimental study on the mother-daughter relationship has been conducted using a combination of cognitive therapy and reality therapy. The results from this method are evaluated better than communication skills training method (Bahram Abadi et al. 2013) because the confusion has improved the mother-daughter relationship in addition to subscales of positive emotion and conversation however it has failed to affect identification (Honar Parvaran, Ghaderi, Amirian zadeh, 2011). Another study in this context compared effect of relationship between religious attitude and parent-child relationship on social adjustment of children of veterans. Results from this research indicated positive effect of child-father relationship on social adjustment of the adolescents (Khoda yari fard, 2004). Khanzadeh et al.(2013) in a study on students in Guilan university put emphasis on variability of addiction and the tendency to opposite sex with parent-child relationship. This research indicated that the more positive emotion and intercourse between mother and father, the rate of addiction reduces. Indeed, the results from regression analysis indicated that father-mother relationship can forecast the addiction in girl and boy students. To sum up, the authors have deduced that if parents fail to make a suitable and constructive relationship with adolescent, the child will be affected by emotional deprivation and this emotional shortage might induce him to addiction and willingness to opposite sex(Khanzadeh, T. Nouri, Yahyazadeh, Isa pour, 2013). Delavar et al.(1998) in a comparative study on harmed children put emphasis on parent-child relationship and marital relationship. This research introduces quality of marital relationship as one of the most important predictors of behavior with child, such that quality of marital relationship determines just $45 \%$ of variance of child abuse. This research indicated that relationships affect each other in the family (Delavar \& Mohammadkhani, 1998). In summary, with regard to the studies, it seems that parent-child relationship can affect aggression(Araghi, 2008), social adjustment(Khodayari fard, 2004), addiction(Khanzadeh, T. Nouri, Yahyazadeh, Isa pour, 2013; Heidarnia \& Charkhian, 2007), academic achievement(Reshvanlu \& Hejazi, 2009, Lavasani, Keivan zadeh, 2007; Ebadi \& Motamedin, 2007), Meta-cognitive and self-control skills(Reshvanlu \& Hejazi, 2009; Darvizeh, 2006), Intrinsic motivation(Reshvanlu \& Hejazi, 2009), selfesteem(Reshvanlu \& Hejazi, 2011), depression in adolescents(Neshat dust, 2003), mental health(Bahrami \& Aslami, 2009; Masiri et al. 2012), antisocial behaviors, emotional disorders such as Obsession , paranoia and phobias(Darvizeh, 2004), assertiveness(Ebadi \& Motamedin, 2007), identity-seeking (Sadeghi, Mehrabi zadeh, Arshadi, 2014). Another research to display significance of parent-adolescent relationship has indicated that the mother-daughter relationship is of greater importance than the value contrast between themselves (Rabani \& Mohammadzadeh, 2012). Effect of parentadolescent relationship on wide range of psychological variables is of great importance of this psychological construct. Some studies have not analyzed the parent-child relationship directly and instead have put emphasis on recognition of attachment. These studies have highlighted the significance of role of safe attachment to parents in identity seeking (Bagheri, Bahrami, Jalali, 2009), the mother-daughter attachment relationship(Jahanbakhsh, Amiri, Molavi, Bahadori, 2010; Safaei, Beigdeli, Tale pasand, 2011), and role of attachment to father in reducing adolescent's behavioral problems(Pakdaman, Seid Mousavi, Ghanbari, 2011). However such studies have highlighted effect of parents' 
attachment on children's attachment, attention to results from these studies indicates that there is a poor relationship between parents' attachment and children's attachment in the populations under study, i.e. if a serious intervention is made in the parent-child relationship, it can modify negative effect of unsafe parents' attachment on children's attachment. Effect of parents' personality traits and parent's relationship with each other has been the subject of research in other studies. Some studies have examined the relationship between parents with each other(Ghareh Baghi, 2010) and marital conflicts(Delavar \& Mohammad khani, 1998) on parent-adolescent relationship; other studies have put emphasis on effect of parents' perfectionism or their neurotic characteristics on the relationship with their child(Ghareh baghi, 2010; Delavar \& Mohammad khani, 1998; Danesh, Kakavand, Salimi nia, 2013; Yazd khasti \& Ghasemi, 2010). These studies have highlighted significance of mutual effects of relationships on each other in human systems.

\section{The Scales Used in Iranian Studies Related to Parent-adolescent Relationship}

The studies at this area indicate that parent-child relationship scale made by Fine, Moreland and Schwebel(1983) has been used to examine the parent-child relationship. The parent-child relationship inventory prepared by Mark A. Fine, John R. Moreland, and Andrew I. Schwebel in form of 24 items is used to measure quality of parent-child relationship. This inventory has two forms that one is used to measure child-mother relationship and the other is used to measure father-child relationship. Two forms are the same for mother and father and just the words mother and father change, yet there are various factors in mother and father forms. Subscales of relationship with father include positive feelings, father Involvement, communications and anger and subscales of relationship with mother include positive emotions, Identification and communication. The parent-child relationship scale with coefficient alpha ranging from 0.89 to 0.94 for subscales related to father and coefficient alpha (0.96) and coefficient alpha ranging from 0.61 to 0.94 for subscales of mother have proper internal consistency, which these alpha coefficients have been obtained by those made the scale by performing the questionnaire on 241 students. In a research conducted by Parhizgar(2003), the calculated coefficients equaled to 0.93 for father form questionnaire and equaled to 0.92 for mother form questionnaire, indicating proper internal consistency. However most of articles at the area of parent-adolescent relationship have used this scale to measure quality of relationship, validation of another scale at this area seems required as believed by authors in the present research. Firstly this scale has been made on the students above 20 years old, while various sources consider adolescence as the age group between 12-18 years old. Yet some more recent sources have known adolescence to the age 21 years old. If we consider adolescence during 12-21 years old, the mentioned scale has considered just two years of these ten years and failed to be used as a scale for all these age groups. The second point is that the scale as the secondary product of another research, i.e. effect of parent's divorce on parent-child relationship has been taken into account, thus the guiding theory behind it is also affected by parental divorce and taken into account by the researchers. Therefore, parent-adolescent relationship has not been spontaneously the subject of research. The third point about internal consistency coefficient of this scale is that its Cronbach's Coefficient Alpha has been reported very high. Cronbach's Coefficient Alpha greater than 0.92 indicates that internal consistency of items is so high assumed that all are measuring one thing, thus various facets of the phenomenon under study have not been taken into account in the aforementioned scale. In addition to the mistakes at the parent-child relationship scale, the components related to adolescent's attachment theory have not been taken into account as the leading theory. Ultimately, with regard to adolescence as the period of age to current social conditions, it seems that validation of a scale to measure parent-child relationship regarding attachment theory will be inevitable.

\section{Components of Parent-child Relationship and Items Related to them}

Multiple articles have studied parent-child relationship in for types of relationships including daughter-mother, mother-son, father-daughter, son-father relationships. They deduced that daughter-mother relationship has been witnessed more than other relationships. Further, they have displayed that quality of these relationships differs from each other. For instance, verbal interactions are witnessed more in daughter-mother relationship, while interactions have been witnessed as making as assignment by mother in mother-son relationship. Therefore, it is better to consider sex difference in formulating the questionnaire. Further, it should take this point into account that parent-adolescent relationship can be studied by both parent and adolescent, i.e. the parent might evaluate their relationship with adolescent proper, but the adolescent has not such understanding from relationship. Therefore, some studies have made attempt to evaluate the adolescent's and parent's understandings from relationship and compare their understandings. Yet there is a significant correlation between their understandings. As a result, the best state is that both sex and role effects are examined concurrently in understanding parent-adolescent relationship. In this regards, the present research has made an attempt 
to study common aspects of these relationships by the adolescent, thus the present scale has measured the adolescent's understanding from parent-adolescent relationship.

\section{Method}

The statistical population consists of all the adolescents at district six of Tehran at secondary grade, studying during 2014-2015. Among 192 high schools and colleges, 5 boy schools and 5 girl schools were selected and the sample size was selected based on cohen's studies (Farahani \& Arizi, 2006,p. 109). With regard to incomplete questionnaires, 273 questionnaires were analyzed. The initial questionnaire has been prepared during the stages below and given to the high school students. At the first stage, the theories related to parent-adolescent relationship and attachment were explored and the features of parent-adolescent relationship were extracted. Further, all the Persian articles performed at the area of parent-adolescent interaction were examined. At the second stage, to prepare the initial scale, a collection consisting of 78 questions in form of multiple items related to "parent-teen relationship" was developed and given to 11 psychologists at this area, asked them to give response to two questions below about each item:

- $\quad$ to which extent the proposed item can adjust to the considered item ?

- $\quad$ to which extent this item can measure the parent-teen relationship?

Ultimately, the items which had received a score higher than $80 \%$ in all three questions above were omitted. As a result, 27 items were omitted and just 51 items were remained. At the third stage, 51 aforementioned questions were given to 45 students at one of the mentioned schools in form of likret scale so as to specify the ambiguous questions and omit them. As a result of factor analysis, 13 other items were removed and ultimately 38 items were prepared to perform the questionnaire. At the fourth stage, the ultimate questionnaire consisting of 38 items together with scales of Depression Anxiety Stress Scales (DASS) was performed among 300 girl and boy students at 10 girl and boy high schools at district six of Tehran. To examine validity of construct at scale and to give response to this question "what are the main components of parent-teen relationship?", factor analysis with main components and Promax rotation was used. Promax rotation is among rotation methods that is used in the scales that their components are not orthogonal to each other.

\section{Analysis of Results}

With regard to results from factor analysis, value of Kaiser-Meyer-Olkin (KMO) index equals to 0.74 . This value is acceptable and as a result factor analysis of the questions has a good justification. Significance of Bartlett's chisquare test in Bartlett's test of sphericity $(\mathrm{p}=0.00)$ indicates that correlation matrix of questions differs from unit matrix, thus it can undergo factor analysis. To extract the factors which are significant developing the infrastructure of test, factor analysis was made at three stages with four factors and Promax rotation, so that the questions with factor loading under 0.45 were omitted at each stage so as to present the structure of questionnaire with 21 items in final form. Factor analysis based on Eigenvalue higher than 1 and coordinates observed in rock chart indicated that it can detect five different factors. These five factors determine $53.29 \%$ of the variance of considered construct and their propositions together with factor loading related to each proposition have been represented in table 1.

Table 1. Ultimate extracted items via factor analysis method with Promax rotation

\begin{tabular}{|l|c|l|}
\hline Name of extracted factor & Factor loading & Item asked in the questionnaire \\
\hline \multirow{4}{*}{ Support } & $0 / 58$ & When something goes wrong, I remember my family. \\
\cline { 2 - 3 } & $0 / 76$ & My parent help me to know myself better \\
\cline { 2 - 3 } & $0 / 63$ & I am equally indebted to my parents \\
\cline { 2 - 3 } & $0 / 50$ & One of my hobbies is going out with my mother \\
\cline { 2 - 3 } & $0 / 66$ & I talk with my parents about my affairs \\
\hline \multirow{5}{*}{ Acceptance } & $0 / 53$ & $\begin{array}{l}\text { When something makes me angry, my father tries to find out the cause of my } \\
\text { discomfort. }\end{array}$ \\
\cline { 2 - 3 } & $0 / 64$ & Sometimes we go for a walk with my father. \\
\cline { 2 - 3 } & $0 / 56$ & My parents respect my views. \\
\cline { 2 - 3 } & $0 / 58$ & I'm not good to my parents how much effort I have. \\
\cline { 2 - 3 } & $0 / 57$ & My parents always reproach to me \\
\cline { 2 - 3 } & $0 / 67$ & I wish that my mother once embrace. \\
\cline { 2 - 3 } & $0 / 71$ & I wish that my father once embrace. \\
\hline
\end{tabular}




\begin{tabular}{|l|c|l|}
\hline \multirow{4}{*}{ Trust } & $0 / 58$ & It is difficult to talk with my mother about my problems. \\
\cline { 2 - 3 } & $0 / 69$ & My parents think I am baby. \\
\cline { 2 - 3 } & $0 / 59$ & Baby Mama are just in the midst of their problems with their parents. \\
\cline { 2 - 3 } & $0 / 56$ & When my farther wants to clean his car, I am happy to help him. \\
\hline Common feeling & $0 / 63$ & If I do something wrong which annoys the parent, they will still love me \\
\cline { 2 - 3 } & $0 / 50$ & My parent and I watch movie together \\
\hline Collaboration & $0 / 73$ & My mother and I cook food together \\
\cline { 2 - 3 } & $0 / 75$ & I help my mother in cleaning the house \\
\cline { 2 - 3 } & $0 / 66$ & If I act contrary to the desire of parents, they do not love me \\
\hline
\end{tabular}

Table 1 displays weight of each of items on each of five factors after removing incorrect items. As explained at bottom of table, promax method has been used to modify the coefficients. In this table, the propositions related to each factor can be observed. These factors differ from the factors considered to prepare the used scale, which some of the initial propositions have been omitted and some belonged to other factors. The names given to factors have been extracted regarding their items. These five items include support, acceptance, trust, common feeling and collaboration. As mentioned, convergent and divergent measures together with an initial questionnaire in form of a booklet were given to the respondents. In addition to validity of construct which was taken into account via factor analysis, the correlation coefficient between these scales with scale "parent-adolescent relationship" was used to evaluate convergent and divergent validity, that the results have been reported in table 2. To measure convergent validity, Coopersmith SelfEsteem Inventories (CSEI) was used; to measure divergent validity, anxiety and depression scale was used. To sum up, it can say that extent of divergent and convergent validity is acceptable for this scale.

Table 2. Correlation coefficient of scale "parent-adolescent relationship" and self-esteem, anxiety and depression as convergent and divergent constructs

\begin{tabular}{|c|c|c|c|}
\hline Self-esteem & DAAS & parent-adolescent relationship & \\
\hline & & 1 & parent-adolescent relationship \\
\hline & 1 & $-0 / 62^{* *}$ & DAAS \\
\hline 1 & $-0 / 54^{* *}$ & $0 / 52^{* *}$ & Self-esteem \\
\hline${ }^{* *} \mathrm{P}<0 / 01 \quad{ }^{*} \mathrm{P}<0 / 05$ & & \\
\hline
\end{tabular}

Further, table below indicates value of Cronbach's alpha related to each of mentioned scales:

Table 3. Value of Cronbach's alpha in the scales used as the internal consistency index of the mentioned scales

\begin{tabular}{|l|c|}
\hline Scale & Cronbach's alpha \\
\hline Parent-adolescent relationship(21 items) & $0 / 86$ \\
\hline Depression and anxiety & $0 / 81$ \\
\hline Self-esteem & $0 / 68$ \\
\hline
\end{tabular}

The values in this table indicate high internal consistency of the scales used in this research.

\section{Conclusion}

However many have known the adolescence with the period of storm and pressure, they know it with its contrasts and conflicts; adolescents are supportive by means of formation of their identity as well as cognitive and emotional changes due to physiologic changes. However, the parents make relationship with adolescent as the way in past. This situation is followed by the conflicts called with inherent property of adolescence by mistake, while these conflicts are not just the inherent property of adolescence but also what appeared due to cognitive, emotional and physiological change at adolescent. Therefore, the present research has made an attempt to examine the parent-adolescent relationship from a different perspective for the purpose of making the scale "parent-adolescent relationship". Since the relationship is a phenomenon belonged to two persons (parent and adolescent) and they are at two different age, it should specify the data should be collected from which age group. In other words, however relationship is the analysis unit, parent and adolescent can be considered as the observation unit. In the present research, with regard to the limitations of the 
research, the adolescent was considered as the observation unit, i.e. data were collected from the adolescent for analysis of parent-adolescent relationship. A variety of studies have examined the parent-adolescent relationship in four types of relationship including daughter-mother, son-mother, father-daughter, son-father relationship. They concluded that motherdaughter relationship is more than other relationships. Further they have displayed that quality of these relationship differs, e.g. verbal relationship is witnessed more in daughter-mother relationship, while relationships appear by making an assignment by mother in son-mother relationship. Thus it is better to prepare a separate scale for each of these relationships and use it in various studies. Further it should take this point into account that the parent-adolescent relationship can be studied by both parent and adolescent, i.e. the parent might evaluate their relationship with adolescent proper, but the adolescent does not have such understanding from the relationship. Therefore some studies have made an attempt to evaluate understanding of adolescent and parent from the relationship and compare them with each other. As result, the best state is to consider both sex effects and role effects of parent. To sum up, since the present research has been conducted just in one of the districts of Tehran, the researchers are suggested to conduct this research in other regions of Iran.

\section{References}

Adlard, L. (2007) The relationship between body dissatisfaction of mothers and body dissatisfaction of their adolescent daughters, Retrieved August 14, 2010, from Nexus electronic database.

Allen, J.P., \& Land, D (1999) Attachment in adolescence, In J. Cassidy \& P.R. Shaver (Eds.), Handbook of attachment: Theory, research and clinical applications. (pp. 319-335). New York: Guilford Press.

Allen, J.P., McElhaney, K.B., Land, D.J., Kuperminc, G.P., Moore, C.W., O'Beirne-Kelly, H., \& Kilmer, S.L. (2003). A secure base in adolescence: Markers of attachment security in mother-adolescent relationships. Child Development, 74, 292-307.

Baltes, M. M., \& Silverberg, S. B. (1994). The dynamics between dependency and autonomy: Illustrations across the life span. In D. L. Featherman, R. M. Lerner, M. Perlmutter (Eds.), Life-span development and behavior (Vol. 12, pp. 41-90). Hillsdale, New Jersey: Erlbaum.

Becker-Stoll, F., \& Fremmer-Bombik, E. (1997, April). Adolescent-mother interaction and attachment: A longitudinal study. Paper presented at the biennial meeting of the society for Research in Child Development, Washington, DC.

Beazer, R. (1998). Adolescent Perspectives of Relationship Quality and Daily Interactions with Their Parents, Virginia Polytechnic Institute and State University

Brown, B, B. Prinstein, M, J. (2011) Encyclopedia of Adolescence, Academic Press is an imprint of Elsevier

Bowlby, J. (1969). Attachment and loss: Vol. 1. Attachment. New York: Basic.

Borkowski, J. G., et al. (2002). The adolescent as parent. In Borkowski, J. G., et al. (Eds) parenting and the child's world. Mahwah, NJ: Lawrence Erlbaum.

Blos, P. (1979). The adolescent passage: Developmental issues. New York: International Universities Press.

Bucx, F. \& Van Wel, F. (2008). Parental bond and life course transitions from adolescent to young adulthood, Adolescence, 43 (169), $71-88$.

Collins, W.A. \& Madsen, S.D. (2006). Personal relationships in adolescence and early adulthood. In D. Perlman \& A. Vangelisti (Eds.), Handbook of personal relationships (pp. 191-209). New York: Cambridge University Press Stellenbosch University http://scholar. sun.ac.za

Collins, W.A. \& Laursen, B. (2004). Parent-adolescent relationships and influences. In R.M. Lerner \& L.D. Steinberg. (Eds.), Handbook of adolescent psychology. (2nd ed.) (pp. 33- 362). New Jersey: John Wiley \& Sons.

Erikson, E.H. (1968). Identity: Youth and crisis. New York: Norton.

Eugenia Scabini (2000), Parent-Child Relationships in Italian Families: Connectedness and Autonomy in the Transition to Adulthood, Psicologia: Teoria e Pesquisa Jan-Abr 2000, Vol. 16 n. 1, pp. 023-030

Field, A (2005) Factor analysis using SPSS

Fine, M. A.; Moreland, J. R.; Schwebel, A. I. (1983). Long-term effects of divorce on parent-child relationships. Developmental Psychology, Vol 19(5, 703-713.

Greenfield, P. M. \& Suzuki, L. (1998). Culture and human development: Implications for parenting, education, pediatrics, and mental health. In I. E. Sigel, \& K. A. Renninger (Eds.), Handbook of child psychology (Fifth Edition), vol. 4: Child psychology in practice (pp. 1059-1109). NY: Wiley.

Grotevant, H. \& Cooper, C. (1986). Individuation in family relationships: A perspective on individual differences in the development of identity and role-taking skills in adolescence. Human Development, 29, 82-100.

Hamilton, C.E. (2000). Continuity and discontinuity of attachment from infancy through adolescence. Child Development, 71 (3), 690694.

Hair, E. C., Moore, K., Garret, S.B., Kinukawa, A., Lippman, L., Michelsen, E. (2003). Psychometric analyses of the parent-adolescent relationship scale in the National Longitudinal Survey of Youth - 1997. Child Trends, 1-31.

Hartup, W.W. \& Laursen, B. (1991). Relationship developmental contexts. In R. Cohen \& A.W. Siegel (Eds.), Context and development. (pp. 253-270). Hillsdale, New Jersey: Erlbaum. 
Hendrick, C., \& Hendrick, S.S. (2000). (Eds.), Close relationships: A source book. Thoasand Oaks, California: Sage.

Leiberman, M., Doyle, A.B., Markiewicz, D. (1999). Attachment to mother and father: Links To peer relations in childhood. Child Development, 70, 202-213.

Marchel, M.A., (2004). Attachment theory: Parent-child relationship revisited. Retrieved July 28, 2008 from http://cehd.umn.edu/ceed/ publications/earlyreport/spring96.htm.

Marinova, D. (2008). Dynamic of parent-child relationships and conflict in Chines, Eastern European and European Canadian families, A thesis presented to the University of Waterloo in fulfillment of the thesis requirement for the degree of Doctor of Philosophy in Psychology

Moore, K.A \& Lippman, L. H. (2005).What Do Children Need to Flourish? Springer

Papalia, D. E., Olds, S.W., \& Feldman, R.D. (2009). Human development. (11th ed.) Boston: McGraw-Hill.

Reis, H. T., Collins, W. A., \& Berscheid, E. (2000). Relationships in human behavior and development. Psychological Bulletin, 126, 844872.

Steinberg, L. (2001). We know some things: Parent-adolescent relationships in retrospect and prospect. Journal of Research on Adolescence, 11 (1), 1-19.

Stryker, S. (1968). Identity salience and role performance: The relevance of symbolic interaction theory for family research. Journal of Marriage and the Family, 30, 558- 564.

West, M., Rose, M.S., Spreng, S., Sheldon-Keller, A. \& Adam, K. (1998), Adolescent attachment questionnaire: A brief assessment of attachment in adolescence. Journal of Youth and Adolescence, 27 (5), 661-673.

Youniss, J., \& Smoller, J. (1985). Adolescent relations with mothers, fathers, and friends. Chicago: University of Chigaco Press. 